\title{
Contemporaneous biopsy and laser interstitial thermal therapy for two treatment-refractory brain metastases
}

\author{
Ashish H. Shah, MD, Angela M. Richardson, MD, PhD, Joshua D. Burks, MD, \\ and Ricardo J. Komotar, MD \\ Department of Neurological Surgery, University of Miami, Florida
}

\begin{abstract}
Recurrent treatment-refractory brain metastases can be treated with modern adjuvant therapies such as laser interstitial thermal therapy (LITT). Since previously radiated lesions may be indolent (treatment effect) or recurrent tumor, histological confirmation may be helpful. The authors present the utility of contemporaneous biopsy and LITT using intraoperative $\mathrm{O}$-arm navigation in a patient who presented with multiple refractory metastases. The authors demonstrate the utility of O-arm navigation to confirm intraoperative biopsy and LITT placement. Concurrent stereotactic biopsy and LITT may be a safe and efficacious method for both the diagnosis and treatment of deep lesions that are unamenable to standard adjuvant treatment modalities.
\end{abstract}

The video can be found here: https://youtu.be/SUY-qiahMyo.

KEYWORDS biopsy; laser; brain metastases; stereotactic

\section{References}

1. Banerjee C, Snelling B, Berger MH, Shah A, Ivan ME, Komotar RJ: The role of magnetic resonance-guided laser ablation in neurooncology. Br J Neurosurg 29:192-196, 2015

2. Diaz R, Ivan ME, Hanft S, Vanni S, Manzano G, Jagid J, et al: Laser interstitial thermal therapy: lighting the way to a new treatment option in neurosurgery. Neurosurgery 79 Suppl 1:S3-S7, 2016

3. Jermakowicz WJ, Diaz RJ, Cass SH, Ivan ME, Komotar RJ: Use of a mobile intraoperative computed tomography scanner for navigation registration during laser interstitial thermal therapy of brain tumors. World Neurosurg 94:418-425, 2016

4. McNichols RJ, Gowda A, Kangasniemi M, Bankson JA, Price RE, Hazle JD: MR thermometry-based feedback control of laser interstitial thermal therapy at $980 \mathrm{~nm}$. Lasers Surg Med 34:48-55, 2004 